\title{
Clinical Drug Trial Participation: Perspectives of Pregnant Women and Their Spouses
}

\author{
Yi Zhao ${ }^{1,2}$ \\ Li Zhang' \\ Yarui Geng'
}

'Women's Hospital, School of Medicine, Zhejiang University, Hangzhou, Zhejiang, 3 I0006, People's Republic of China; ${ }^{2}$ Department of Drug Clinical Trials, Women's Hospital, School of Medicine, Zhejiang University, Hangzhou, Zhejiang, 310006, People's Republic of China
Correspondence: Yi Zhao

Department of Drug Clinical Trials, Women's Hospital, School of Medicine, Zhejiang University, Hangzhou, Zhejiang, 310006, People's Republic of China

$\mathrm{Tel} / \mathrm{Fax}+86$ 57I-8706I50I

Email zhaoyil124@zju.edu.cn
Objective: This study aimed at investigating the factors influencing clinical drug trial participation by pregnant women and their spouses.

Methods: This hospital-based cross-sectional study was conducted at Women's Hospital, School of Medicine, Zhejiang University, from July to September 2020. A self-administered questionnaire was distributed to pregnant women and their spouses in the maternity ward The questionnaire consisted of two sections: The first part was aimed at collecting demographic information data while the second part consisted of 10 open-ended questions regarding clinical drug trial knowledges, financial compensation, risk awareness, psychological impact, and pregnancy outcomes.

Results: A total of 206 questionnaires (115 from pregnant women and 91 from their spouses) were included in the statistical analysis. About $50 \%$ of pregnant women and their spouses had heard of clinical trials $(50.43 \%$ vs $49.45 \%, \mathrm{p}=0.888)$. Compared to their spouses, the proportion of pregnant women who thought that there is a need for the development of drugs during pregnancy was significantly higher $(94.78 \%$ vs $16.48 \%$, $\mathrm{p}=0.008$ ). Moreover, a significant number of full-time employed pregnant women believed that clinical drug trials will increase the possibility of disease cure, relative to part-time/not employed pregnant women $(98.21 \%$ vs $88.13 \%, \mathrm{p}=0.030)$. Spouses whose education levels were below high school and those whose education level was high school or above exhibited significant differences regarding whether financial compensation will motivate their participation in clinical trials $(77.78 \%$ vs $58.90 \%, \mathrm{p}=0.044)$. Pregnant women and their spouses had no significant differences regarding various aspects: drug treatment during pregnancy, clinical trial drugs should be free, the need to increase the protection of pregnant women in clinical trials.

Conclusion: Due to fetus-associated concerns, most pregnant women are reluctant to be included in clinical trials. However, pregnant women and their spouses agree that medical treatment should be accessible for illnesses during pregnancy, and clinical drug trials during pregnancy should be performed. The usage of untested or sub-therapeutic drug regimens in clinical practice paradoxically increases the risk for fetuses. When recruiting pregnant volunteers for clinical drug trials, researchers should conduct in-depth consultations and comprehensively inform the pregnant women and their families on the pros and cons of their involvement.

Keywords: pregnancy, clinical trials, drug safety, participation, attitudes

\section{Introduction}

Although pregnant women have concerns regarding drug safety, many of them take medications during pregnancy due to illness or pregnancy reactions. During pregnancy, about $58 \%$ to $97 \%$ of women take at least one drug. ${ }^{1}$ The safety and 
effectiveness of the drugs used by pregnant women should have been proven, and more than half of pregnant women and their spouses have perceived needs for information about the safety and use of medications during pregnancy. ${ }^{2}$ However, the vast majority of newly marketed drugs have no reported human pregnancy experience. This is because pregnant women are routinely excluded from clinical trials because of ethical considerations and the fear of potential fetal harm. ${ }^{3-5}$

In the past few decades, bioethicists, pharmacologists, regulators, and researchers elucidated on the need to include pregnant women in clinical trials to improve knowledge regarding the safety, dosage, and long-term effects drugs on pregnant women. ${ }^{6-8}$ Medical associations and regulatory agencies in various countries have been advocating for the removal of obstacles for pregnant women to be included in drug clinical research. ${ }^{6,7,9}$ The US FDA passed the "Pregnancy and Lactation Labeling Final Rule" (PLLR, Final Rule) in 2014. The rule requires an evaluation of the available information about a product's use in pregnancy, which is expected to advance the development and implementation of clinical research on pregnant women. ${ }^{10}$ "Review Methods of Biomedical Research Ethics Involving Human Beings" passed by the National Health Commission of China emphasize on the protection of pregnant women and fetuses, ${ }^{11}$ but there is no precise method or plan in the document. Currently, there are no published laws or guidelines for drug clinical trials involving pregnant women in mainland China.

The willingness of patients to participate in a given clinical trial is a sine qua non for that trial to be conducted. However, it is exceedingly challenging to recruit pregnant women as study participants because that a majority of pregnant women are the fear of potential fetal harm and lack of knowledge in clinical experiments. ${ }^{12,13}$ At present, there are few studies on the motivation of pregnant women to participate or not to participate in clinical trials, especially the views of pregnant women's spouses. Thus, the principal objective of this project was to investigate the attitudes of the pregnant women and their spouses about participation in clinical trials to determine if this is one of the barriers to the involvement of this population in clinical trials.

\section{Materials and Methods}

\section{Study Sample}

Pregnant women and their spouses in the maternity ward of Women's Hospital, School of Medicine, Zhejiang
University were invited to participate in the questionnaire survey. This survey was conducted from July to September 2020. Pregnant women and their spouses (age $>18$ years) who agreed to participate in this study were enrolled. However, pregnant women or their spouses whose physical or mental health (including reading difficulties and dysgraphia) prevented them from providing information were excluded.

This study was conducted in accordance with the Declaration of Helsinki. ${ }^{14}$ Signed informed consents were obtained from all participants. Ethical approval was obtained from the Ethical Committee of Women's Hospital, School of Medicine, Zhejiang University (Ref: IRB-20200182-R).

\section{Study Design}

The study purpose and procedures were carefully explained to all participants by three trained study staff, and any questions were answered. Based on current literature, the questionnaire was developed by the investigators and pre-tested before the baseline survey. One-hour semistructured interviews were completed with ten pregnant women and their spouses to assess content validity, content consistency, readability and comprehension, possible defects, and the time required to complete the questionnaire. The final questionnaire comprised five categories with a total of 10 items. Participants was informed by the three trained study staff and asked whether pregnant women or their spouses were willing to participate according to the order of patients' admission to the hospital.

According to the requirement of establishing sample size of early questionnaire, the sample size should be at least 4 times of the number of questionnaire items, ${ }^{15,16}$ while some studies suggest that a sample size minimum was based on a subject to variable ratio of 5:1 and an optimal sample size based on a subject to variable ratio of 10:1. ${ }^{17,18}$ This questionnaire had 10 items, considering no response bias, and the sample size should be increased by $5 \%$. Therefore, the ideal sample size $=10 * 10 *(1+5 \%)$ $* 2=210$.

The questionnaire consisted of two sections: The first section surveyed demographic information, including age, occupation, education, urban or rural residence, religious affiliation, marital status, income, and health insurance status. The second section consisted of 10 open-ended questions were asked questions regarding drug clinical trials, whether they had heard of drug clinical trial, whether sick-pregnant woman should be medicated, and 
whether it is necessary to develop drugs for pregnant women. They also answered the questions regarding financial compensation, risk awareness, psychological impact, and pregnancy outcomes.

\section{Statistical Analysis}

Data were analyzed by the SPSS statistical software (version SPSS 20.0, IBM SPSS Inc, Chicago, IL, USA). Count data are expressed as percentages (\%), while measurement data are presented as mean \pm S.D. Comparison of means between groups was performed by an independent samples $t$-test or Mann-Whitney $U$-test. $\alpha=0.05$ was the test level, $\mathrm{p} \leq 0.05$ indicated statistically significant differences.

\section{Results}

\section{Demographics of the Respondents}

A total of 210 questionnaires were distributed to the study participants, 4 were excluded because they were incomplete, and 206 were finally included in the statistical analyses. Among them, 115 questionnaires had been completed by pregnant women while 91 questionnaires had been completed by their spouses. Of the 115 pregnant women, 10 had pregnancy complications, 63 had been admitted because of labor, while 42 had already delivered. There were no significant in age, educational level, insurance, previous birth, or income $(\mathrm{p}>0.05)$. The percentage of full-time employed spouses $(65.9 \%)$ was significantly higher than that of part-time/non employed spouses (34.4\%) (Table 1).

\section{Attitudes of Pregnant Women and Their Spouses Regarding Participation in Clinical Trials}

There were no significant differences between the proportions of pregnant women and their spouses, who had heard of clinical trials $(50.43 \%$ vs $49.45 \%$, respectively; $p>$ $0.05)$. The proportions of pregnant women who thought drug clinical trials will increase the possibility of cure was significantly higher than that of their spouses $(p=0.001)$. The majority of pregnant women and their spouses believed that medications should be used to treat illnesses during pregnancy. However, there were significant differences regarding whether it is necessary to develop drugs for pregnant women. Approximately $94.78 \%$ of pregnant women believed that there is a need to develop drugs for pregnant women, with only $16.48 \%$ of their spouses believing that it is necessary $(\mathrm{p}=0.008)$. Pregnant women exhibited similar views to those of their spouses and believed that drugs in clinical trials should be free, and that pregnant women who choose to participate in drug clinical trials should be more protected than others. Approximately $69.57 \%$ of pregnant women and $81.32 \%$ of their spouses did believe that participation in clinical trials will lead to discrimination against them and their

Table I Demographic Characteristic of Study Participants

\begin{tabular}{|c|c|c|c|c|}
\hline Characteristic & Classification & Pregnant Women(\%)(n= I I5) & Husband(\%)(n=91) & p-value \\
\hline \multirow[t]{2}{*}{ Age (year) } & $<35$ & $102(88.7)$ & $76(83.5)$ & \multirow[t]{2}{*}{0.383} \\
\hline & $\geqq 35$ & $13(11.3)$ & $15(16.5)$ & \\
\hline \multirow[t]{2}{*}{ Educational level } & Less than high school & $21(18.3)$ & $18(19.8)$ & \multirow[t]{2}{*}{0.940} \\
\hline & High school or more & $94(69.6)$ & $73(69.2)$ & \\
\hline \multirow[t]{2}{*}{ Employment } & Full time & $56(49.6)$ & $60(65.9)$ & \multirow[t]{2}{*}{0.032} \\
\hline & Part time/not employed & $59(51.3)$ & $31(34.4)$ & \\
\hline \multirow[t]{2}{*}{ Insurance } & Uninsured & $8(7.0)$ & $12(13.2)$ & \multirow[t]{2}{*}{0.147} \\
\hline & Maternity insurance/Medicare/Medicaid & $107(93.0)$ & $79(86.8)$ & \\
\hline \multirow[t]{2}{*}{ Previous birth } & No & $41(35.7)$ & $28(30.8)$ & \multirow[t]{2}{*}{0.556} \\
\hline & $\geq 1$ & $74(64.3)$ & $63(69.2)$ & \\
\hline \multirow[t]{3}{*}{ Income (per month) } & $<10,00$ RMB & $3(2.61)$ & $3(3.30)$ & \multirow[t]{3}{*}{$0.196^{\mathrm{a}}$} \\
\hline & 10,00-50,00 RMB & $18(15.65)$ & $10(10.99)$ & \\
\hline & $>5000$ RMB & $94(81.74)$ & 78 (85.72) & \\
\hline
\end{tabular}

Notes: p-values of educational level, employment, employment, previous birth were obtained from Mann-Whitney U-test; p-values of age and income were obtained from independent sample $t$-test; ${ }^{a}$ Income per month $\leq 5000$ RMB vs $>5000$ RMB. 
offsprings while $93.04 \%$ of pregnant women and $91.21 \%$ of their spouses did not believe in terminating pregnancy in order to participate in drug clinical trials $(\mathrm{p}=0.625$; Table 2).

\section{Effects of Pregnancy History on Willingness to Participate in Clinical Trials}

Most of the perspectives for women without a history of pregnancy and their spouses and those with a history of pregnancy and their spouses were not significantly different. However, there were significant differences perspectives regarding drugs development for pregnant women. The proportion of women without a history of pregnancy and their spouses who believed in the needs to develop drugs for pregnant women was significantly higher than when compared to those with a history of pregnancy and their spouses $(100 \%$ vs $91.89 \% ; 89.29 \%$ vs $80.95 \%$; Table 3).

\section{Effects of Employment on the Willingness of Pregnant Women to Participate in Clinical Trials}

Most of the perspectives of full-time employed pregnant women and those part-time/non employed pregnant women were not significantly different. However, there were significant differences regarding whether drug clinical trials can increase the possibility of disease cure ( $98.21 \%$ vs $88.13 \%, p=0.030$; Table 4$)$.

\section{Effects of Educational Levels of Pregnant Women's Spouses on Participation in Clinical Trials}

Most of perspectives for spouses with different educational levels were not significantly different. However, there were significant differences in perspectives regarding whether financial compensation can motivate them to participate in clinical trials (Less than high school vs High school or more $=77.78 \%$ vs $58.90 \%, p=0.044$; Table 5 ).

\section{Discussion}

Ethical reasons preclude the inclusion of pregnant women in the vast majority of premarketing clinical trials for a long time, ${ }^{19-21}$ however, most women use more than one pharmaceutical drug during pregnancy that they did not use previously, in addition to vitamin/mineral supplements required during that time, ${ }^{22,23}$ but these pharmaceutical drug is often based on limited scientific evidence insofar as the drug $\mathrm{s}$ safety and effectiveness are concerned. Indeed, most of the relevant studies were performed in non-pregnant women, so the data generated may not apply to pregnant women. ${ }^{24}$ Given these considerations, pregnant women were excluded from previously drug clinical trials can be challenged. ${ }^{8,19,25}$

As the policies and regulations about pregnant women including clinical trials were refined, many researchers focus to women's views about participating in clinical trials while pregnant. ${ }^{26-29}$ Several studies deemed pregnant women are unwilling to involving clinical trials because of women reluctance to exposing themselves and their fetus to a treatment that is still undergoing evaluation. ${ }^{30,31}$ Another study showed that the principal motivating factor in the decision to participate in a clinical trial was how well the study was explained by the recruiters, but the risk of unknown side effects was the principal barrier. $^{31}$

A specific strength of our study is that we investigate the attitudes of the pregnant women and their spouses about participation in clinical trials, rather than just pregnant women. About $38 \%$ of survey respondents had heard of drug clinical trials, and $93.04 \%$ of pregnant women and $75.82 \%$ of their spouses believe that drug clinical trials could increase the possibility of disease cure. However, there were differences in opinion regarding whether it is necessary to develop drugs for pregnant women with $94.78 \%$ of pregnant women believing that they need to be developed, and only $16.48 \%$ of spouses believing that it is necessary. Therefore, pregnant women's spouses are more reluctant to include pregnant women in clinical trials than pregnant women. We suggest that when recruiting pregnant women into clinical trials, researchers should fully explain the clinical implications to their spouses so that pregnant women and their spouses can decide whether to participate. We did not obtain evidence supporting the reasons for pregnant women's spouses are more reluctant to include pregnant women in clinical trials than pregnant women, as there was no relevant literature to date, so we can only speculate what the reason for this is. Pregnant women have a longer contact with recruiters through daily prenatal testing compared with their spouses, so pregnant women are more profound in clinical trials. This observation is consistent with other studies showing that the principal motivating factor in the decision to participate in a clinical trial was how well the study was explained by the recruiters. ${ }^{31}$ Alternatively, or in addition, for pregnant 


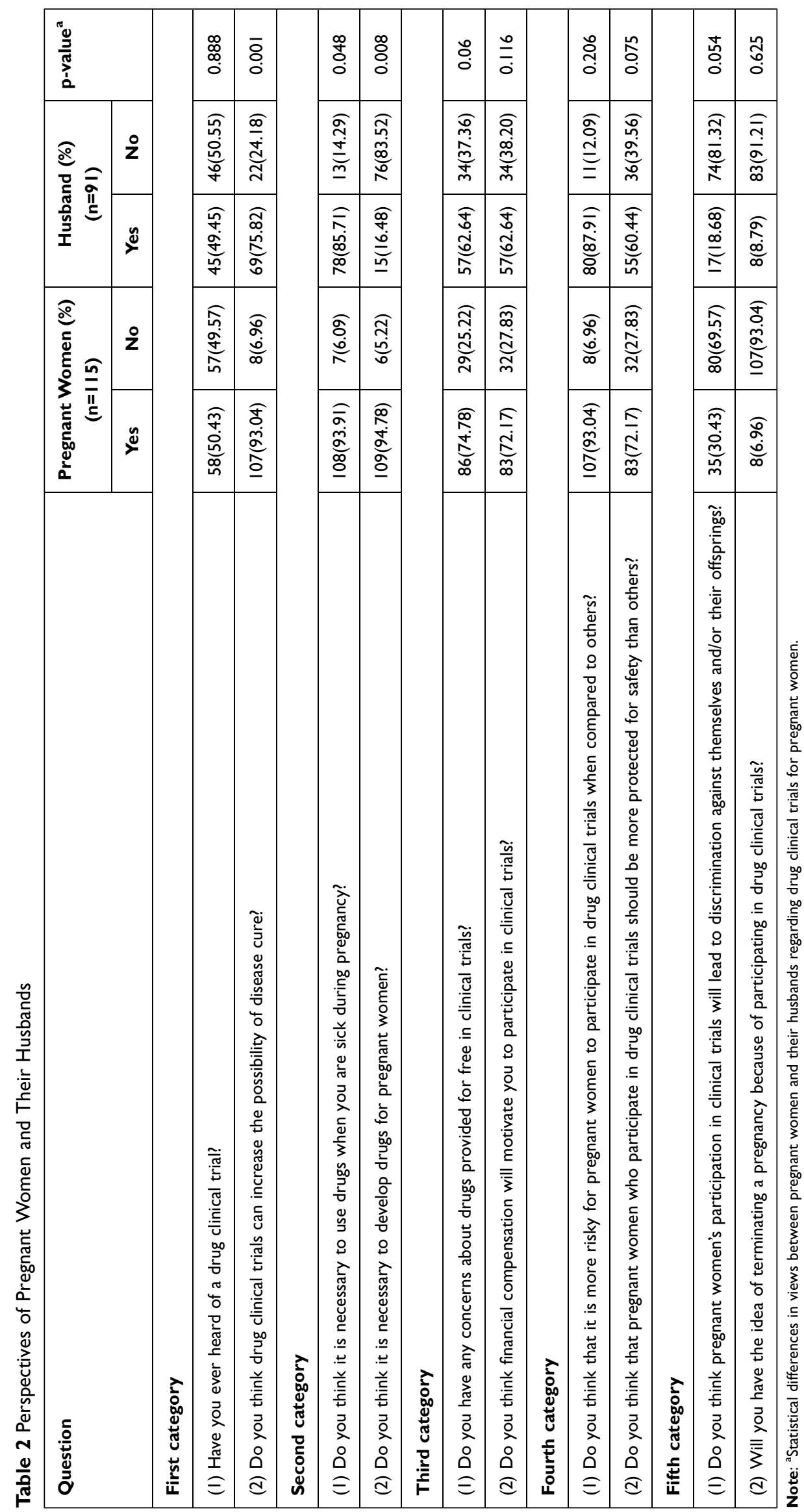




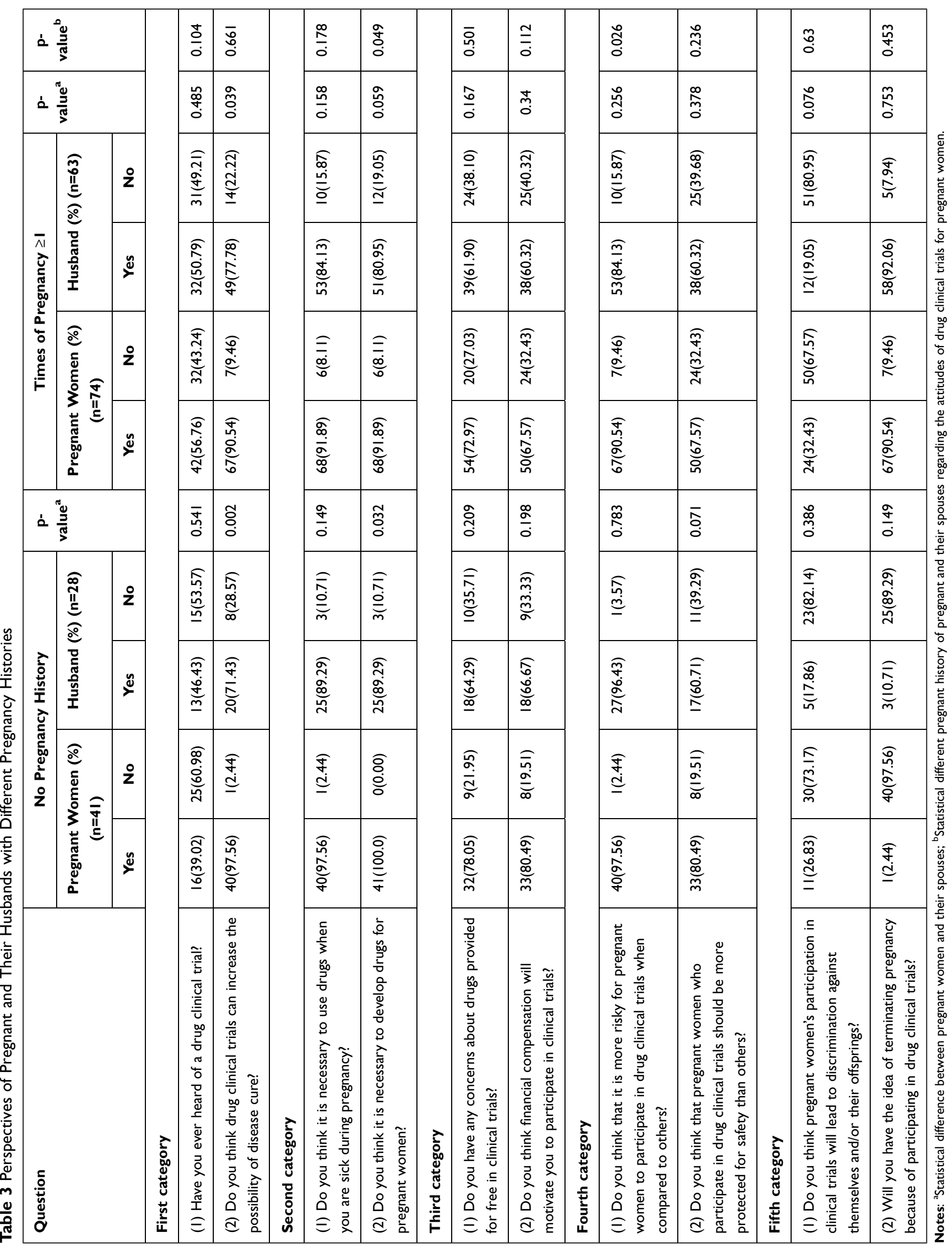




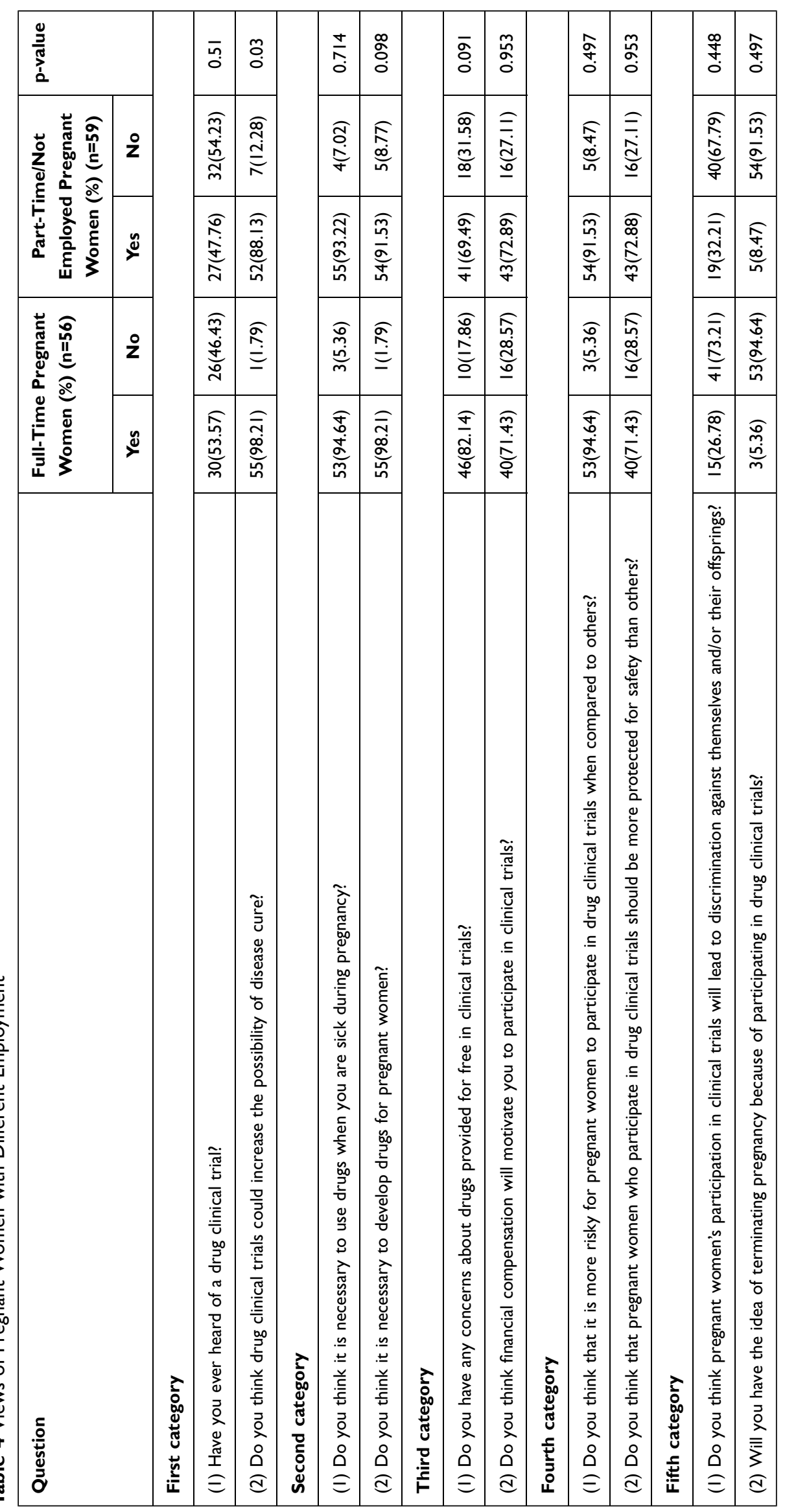




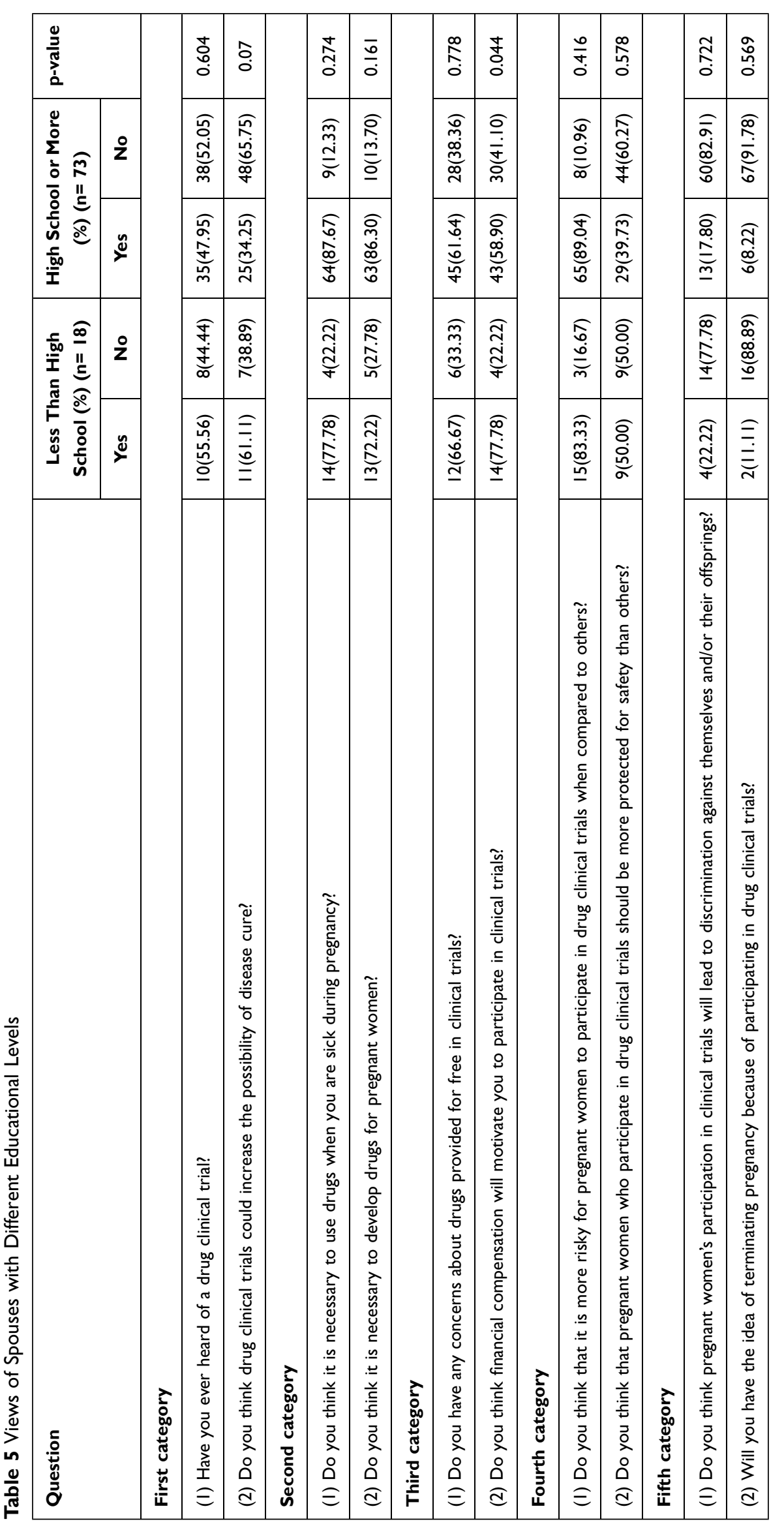


women, it is possible that they were more worried about abortion or fear of reexposure to pregnancy.

Regarding medication costs in clinical trials, pregnant women and their spouses agree that clinical trials should be free. However, $72.17 \%$ of pregnant women and $62.64 \%$ of spouses believe that financial compensation will motivate them to participate in clinical trials. A global survey of registered clinical trials of pharmacological interventions in pregnancy conducted in 2016 showed that just $0.32 \%$ of all active registered studies were pregnancy drug trials (PDTs). The majority of PDTs focused on anesthesia/analgesia, preterm birth/ tocolysis, labor induction, endocrine, and hypertensive disorders. Pharmaceutical companies fund only $7 \%$ of PDTs. $^{32}$ Governments and charitable funds should increase their support for PDTs. The government should introduce relevant incentive policies to support pharmaceutical companies to invest in PDTs. Sheffield believes33 that pharmaceutical industries and researchers are reluctant to research on pregnant women because of ethical considerations or fear that the lack of legislative authorization or incentives for such high-risk research will bring risks to pregnant women and fetuses. Therefore, there is an urgent need to improve of PDTs regulations.

The proportion of women without a history of pregnancy and their spouses who believed that it is necessary to develop drugs for pregnant women was significantly higher than that of women with pregnancy history and their spouses. In-depth studies should be performed to determine whether this outcome is attributed to the small sample size or whether pregnant women without a history of pregnancy and their spouses are more worried about the drug's safety or other reasons.

Different educational levels for the spouses of pregnant women were significant differences in whether financial compensation will motivate them to participate in clinical trials. The average annual income for spouses with less than high school education was 97,600 yuan and 157,800 yuan for those with a high school education or more. Therefore, we postulate that income differences are attributable to the above-mentioned differences. We are conscious that the questionnaire of clinical experiments should not involve economic motivations, but the purpose of this study to investigate whether participants with different income levels and different insurance conditions have different perspectives.

\section{Conclusion}

Due to concerns about the fetus, it is common for pregnant women to be reluctant to be included in clinical trials. However, pregnant women and their spouses agree that medical treatment should be given for illnesses during pregnancy, and clinical trials of drugs during pregnancy should be performed. This practice paradoxically increases the risk of fetuses using untested or sub-therapeutic drug regimens in clinical practice, especially the idea of their spouses. When recruiting pregnant volunteers for clinical trials, researchers should conduct in-depth consultations and education on drug clinical trials for pregnant women and their families and give a comprehensive introduction to trial drugs, to reduce the prejudice of pregnant women and their families for clinical trials.

\section{Acknowledgments}

The work was supported by grants from the Zhejiang Provincial Natural Science Foundation (GF21F020055).

\section{Disclosure}

The authors report no conflicts of interest in this work.

\section{References}

1. Meyer A, Fermaut M, Drouin J, Carbonnel F, Weill A. Drug use for gastrointestinal symptoms during pregnancy: a French nationwide study 2010-2018. PLoS One. 2021;16(1):e0245854. doi:10.1371/journal.pone. 0245854

2. Truong MBT, Ngo E, Ariansen H, Tsuyuki RT, Nordeng H. Community pharmacist counseling in early pregnancy-Results from the SafeStart feasibility study. PLoS One. 2019;14(7):e0219424. doi:10.1371/journal.pone.0219424

3. van der Straten A, Ryan JH, Reddy K, et al. Influences on willingness to use vaginal or oral HIV PrEP during pregnancy and breastfeeding in Africa: the multisite MAMMA study. J Int AIDS Soc. 2020;23(6): e25536.

4. Saito M, Gilder ME, Nosten F, McGready R, Guérin PJ. Systematic literature review and meta-analysis of the efficacy of artemisinin-based and quinine-based treatments for uncomplicated falciparum malaria in pregnancy: methodological challenges. Malar J. 2017;16(1):488. doi:10.1186/s12936-017-2135-y

5. Kreuder AE, Bolaños-Rosales A, Palmer C, et al. Inspired by the human placenta: a novel 3D bioprinted membrane system to create barrier models. Sci Rep. 2020;10(1):15606. doi:10.1038/s41598-02072559-6

6. Lyerly AD, Little MO, Faden R. The second wave: toward responsible inclusion of pregnant women in research. Int $J$ Fem Approaches Bioeth. 2008;1(2):5-22. doi:10.3138/ijfab.1.2.5

7. Payne P. Including pregnant women in clinical research: practical guidance for institutional review boards. Ethics Hum Res. 2019;41 (6):35-40. doi:10.1002/eahr.500036

8. White A. Accelerating the paradigm shift toward inclusion of pregnant women in drug research: ethical and regulatory considerations. Semin Perinatol. 2015;39(7):537-540. doi:10.1053/j.semperi.2015.08.008 
9. Allesee L, Gallagher CM. Pregnancy and protection: the ethics of limiting a pregnant woman's participation in clinical trials. J Clin Res Bioeth. 2011;2(108). doi:10.4172/2155-9627.1000108

10. Gruber MF. The US FDA pregnancy lactation and labeling rule Implications for maternal immunization. Vaccine. 2015;33(47):64996500. doi:10.1016/j.vaccine.2015.05.107

11. National Health Commission of China. Review method of biomedical research ethics involving human beings; 2016.

12. Meshaka R, Jeffares S, Sadrudin F, Huisman N, Saravanan P. Why do pregnant women participate in research? A patient participation investigation using Q-Methodology. Health Expect. 2017;20 (2):188-197. doi:10.1111/hex.12446

13. Wada K, Evans MK, de Vrijer B, Nisker J. Clinical research with pregnant women: perspectives of pregnant women, health care providers, and researchers. Qual Health Res. 2018;28(13):2033-2047. doi:10.1177/1049732318773724

14. World Medical Association. World Medical Association Declaration of Helsinki: ethical principles for medical research involving human subjects. JAMA. 2013;310(20):2191-2194. doi:10.1001/jama.2013.281053

15. Schwab D. Construct validity in organizational behavior. Res Organ Behav. 1980;2(1):3-43.

16. Rummel RJ. Applied Factor Analysis. Northwestern University Press; 1970.

17. MacCallum RC, Widaman KF, Preacher KJ, Hong S. Sample size in factor analysis: the role of model error. Multivariate Behav Res. 2001;36(4):611-637. doi:10.1207/S15327906MBR3604_06

18. Mealy RN, Richardson LA, Miller B, Smith M, Juvancic-Heltzel JA. Exercise is medicine $\left({ }^{\circledR}\right)$ : knowledge and awareness among exercise science and medical school students. Int J Exerc Sci. 2019;12(3):505-514.

19. Isoherranen $\mathrm{N}$, Thummel KE. Drug metabolism and transport during pregnancy: how does drug disposition change during pregnancy and what are the mechanisms that cause such changes? Drug Metab Dispos. 2013;41(2):256-262. doi:10.1124/dmd.112.050245

20. Lupattelli A, Spigset O, Twigg MJ, et al. Medication use in pregnancy: a cross-sectional, multinational web-based study. BMJ Open. 2014;4(2):e004365. doi:10.1136/bmjopen-2013-004365

21. Taylor MM, Kara EO, Araujo MAL, et al. Phase II trial evaluating the clinical efficacy of cefixime for treatment of active syphilis in non-pregnant women in Brazil (CeBra). BMC Infect Dis. 2020;20 (1):405. doi:10.1186/s12879-020-04980-1

22. Derauf C, Kekatpure M, Neyzi N, Lester B, Kosofsky B. Neuroimaging of children following prenatal drug exposure. Semin Cell Dev Biol. 2009;20(4):441-454. doi:10.1016/j.semcdb.2009.03.001
23. Matsui D. Adherence with drug therapy in pregnancy. Obstet Gynecol Int. 2012;2012:796590. doi:10.1155/2012/796590

24. Haas DM, Marsh DJ, Dang DT, et al. Prescription and other medication use in pregnancy. Obstet Gynecol. 2018;131(5):789-798. doi:10.1097/AOG.0000000000002579

25. Salas SP. Ethical challenges posed by clinical trials in preterm labor: a case study. Reprod Health. 2017;14(Suppl 3):168. doi:10.1186/ s12978-017-0427-x

26. Lyerly AD, Namey EE, Gray B, Swamy G, Faden RR. Women's views about participating in research while pregnant. Ethics Hum Res. 2012;34(4):1-8.

27. Monteiro TM, Katz L, Bento SF, Amorim MM, Moriel PC, Pacagnella RC. Reasons given by pregnant women for participating in a clinical trial aimed at preventing premature delivery: a qualitative analysis. BMC Pregnancy Childbirth. 2019;19(1):97. doi:10.1186/ s12884-019-2240-8

28. Wilcox CR, Calvert A, Metz J, et al. Attitudes of pregnant women and healthcare professionals toward clinical trials and routine implementation of antenatal vaccination against respiratory syncytial virus: a multicenter questionnaire study. Pediatr Infect Dis J. 2019;38 (9):944-951. doi:10.1097/INF.0000000000002384

29. McQuaid F, Pask S, Locock L, et al. Attitudes towards antenatal vaccination, Group B streptococcus and participation in clinical trials: insights from focus groups and interviews of parents and healthcare professionals. Vaccine. 2016;34(34):4056-4061. doi:10.1016/j.vaccine.2016.06.024

30. Strömmer S, Lawrence W, Rose $\mathrm{T}$, et al. Improving recruitment to clinical trials during pregnancy: a mixed methods investigation. Soc Sci Med. 2018;200:73-82. doi:10.1016/j.socscimed.2018.01.014

31. Myles S, Tocci C, Falk M, et al. A multicenter investigation of factors influencing women's participation in clinical trials. $J$ Womens Health. 2018;27(3):258-270. doi:10.1089/jwh.2017.6458

32. Scaffidi J, Mol BW, Keelan JA. The pregnant women as a drug orphan: a global survey of registered clinical trials of pharmacological interventions in pregnancy. BJOG. 2017;124(1):132-140. doi: $10.1111 / 1471-0528.14151$

33. Sheffield JS, Siegel D, Mirochnick M, et al. Designing drug trials: considerations for pregnant women. Clin Infect Dis. 2014;59(Suppl 7):S437-S444. doi:10.1093/cid/ciu709
Patient Preference and Adherence

\section{Publish your work in this journal}

Patient Preference and Adherence is an international, peer-reviewed, open access journal that focusing on the growing importance of patient preference and adherence throughout the therapeutic continuum. Patient satisfaction, acceptability, quality of life, compliance, persistence and their role in developing new therapeutic modalities and compounds to optimize clinical outcomes for existing disease states are major areas of interest for the journal. This journal has been accepted for indexing on PubMed Central. The manuscript management system is completely online and includes a very quick and fair peer-review system, which is all easy to use. Visit http:// www.dovepress.com/testimonials.php to read real quotes from published authors. 